\title{
Structural and temporal dynamics of the bee curtain in the open-nesting honey bee species, Apis florea
}

\author{
Hemalatha BHAGAvAN $^{1,2}$, Oliver MuthMANN ${ }^{1,2}$, Axel BrocKMANN ${ }^{1}$ \\ ${ }^{1}$ National Centre for Biological Sciences, Tata Institute of Fundamental Research, Bangalore, India \\ ${ }^{2}$ Manipal University, Manipal, India
}

Received 29 August 2015 - Revised 29 December 2015 - Accepted 11 January 2016

\begin{abstract}
Workers of open-nesting honey bee species form a bee curtain to cover the comb and protect it against adverse environmental conditions and predators. We studied different aspects of structural and temporal dynamics of the bee curtain in Apis florea. First, in the course of daily observations, we discovered massed flight activity (MFA) of A. florea colonies similar to that previously described for A. dorsata. The MFAs started with the opening of gaps in the curtain and appearance of chains of bees shortly before the massed take off. Second, monitoring the worker movement patterns in the outer layer indicated a constant turnover of bees in the curtain. Finally, introduction of marked 1-day-old workers showed that workers joined the curtain at a very young age. First flight activity appeared around day 20 , but the majority of workers started to fly after day 47 , which is twice the age at which $A$. mellifera workers start to forage.
\end{abstract}

\section{Apis florea / open-nesting / bee curtain / massed-flight activity}

\section{INTRODUCTION}

One of the most striking differences among honey bee species is their nesting behavior. Colonies of the Apis mellifera and other cavity-nesting species build nests composed of several combs sheltered in a tree trunk or other cavities (Seeley and Morse 1976; Hepburn et al. 2014). In contrast, the opennesting honey bees of the tropics, including Apis florea and Apis dorsata, build only a single comb, which is attached to a branch or an overhang. The majority of workers form a curtain of multiple layers that cover the comb (Ruttner 1988; Dyer and Seeley 1991; Oldroyd and Wongsiri 2006; Phiancharoen et al. 2011). This bee curtain

Electronic supplementary material The online version of this article (doi:10.1007/s13592-016-0428-8) contains supplementary material, which is available to authorized users.

Corresponding author: A. Brockmann, axel@ncbs.res.in

Manuscript editor: James Nieh functions as a protective shield against unfavorable environmental conditions (e.g., rain, temperature) and predators (e.g., birds, wasps) (Dyer and Seeley 1991; Oldroyd and Wongsiri 2006). For instance, a number of different collective defensive movement patterns and sounds produced by the workers in the curtain have been reported (Kastberger et al. 2011; Fuchs and Tautz 2011). In addition, a unique form of a short-lived "massed flight activity" (MFA) was observed in A. dorsata and A. laboriosa colonies, but the function of this behavior is still unclear (Batra 1996; Kastberger et al. 1996; Woyke et al. 2003).

Besides its immediate functions, the bee curtain probably has a significant effect on the age structure and division of labor in open nesting honey bee species. Seeley et al. (1982) suggested that cavitynesting provides the possibility of disbanding the bee curtain and the allocation of more workers for foraging and brood care, which in turn affects colony demography, age-polyethism, and individual behavior. Unfortunately, further studies corroborating Seeley's ideas are still missing. 
Here, we present a study on three different aspects of the structural and temporal dynamics of the bee curtain in A. florea : (a) occurrence and temporal dynamics of massed flight activity, (b) daily movement patterns of individual workers in the outermost layer of the curtain, and (c) agerelated changes in curtain activities and onset of flight behavior (as a proxy for foraging).

\section{MATERIALS AND METHODS}

All experiments were carried out with wild $A$. florea colonies $(N=10)$ which were caught on or near the campus of the National Centre for Biological Sciences (NCBS) in Bangalore, India. We mounted the colonies in an open custom-made box (17 in $\times 33$ in) or simply attached them to a tree branch. Colonies stayed at the experimental sites for a minimum of 2 weeks to a maximum of 4 months. Experiments were performed between December 2012 and July 2015.

\subsection{Observation and video recording of colonies}

Colonies were kept in an open wooden box, and a camera was placed on a permanently fixed tripod stand at a distance of $1.5 \mathrm{~m}$. All the video-recordings were done using a SONY HDR-CX260 at the rate of $60 \mathrm{fps}$ (frames/second). Ambient temperature was measured at the onset of MFAs. Daily mean temperatures in Bangalore were obtained from "World Weather" Tutiempo Network (http://en.tutiempo.net).

\subsection{Paint marking of bees}

We used Uni POSCA Paint Markers (Uni Mitsubishi Pencil, UK) to paint mark worker bees. The paint marking lasted for more than 2 months. We did not observe any apparent negative effects on the behavior, for example, paint marked bees were readily accepted by the colonies.

\subsection{Analysis of MFA}

We observed the massed flights (4-5) of four colonies for a detailed analysis and description of MFAs. The four colonies were observed during different times of the year (2012: December; 2013: April, August, and October). Each day, we observed and recorded the curtain of the colonies from 1130 hours until the end of the MFA.

We determined the temporal dynamics of MFAs by counting the number of bees in flight (seen as dark blurred objects in the video frame) for $1 \mathrm{~s}$ (i.e., 60 frames) of 1-min intervals of the recordings. In addition, we counted the number of bees walking downward on the curtain for every $30 \mathrm{~s}$. Down-walking bees were identified easily when the videos were watched at $1.5 \times$ speed. The temporal dynamics of the reorientation process were determined by measuring the relative curtain area covered with vertically oriented bees for every $1 \mathrm{~min}$.

\subsection{Daily movement patterns of individual workers on the curtain}

We used two colonies to monitor daily activity patterns of individually identified workers in the curtain (February and May 2014). In each experiment, we caught around 100 workers, paint-marked them for individual identification (Uni POSCA Paint Markers, see Figure S1) and introduced them back into their colony. The colonies were observed for the whole day (0630 hours until 1820 hours, and 1930 hours, respectively). For the final analysis, we selected 21 bees that appeared before 1400 hours and also reappeared on the curtain at least once during the later part of the day. Small-scale spatial motion of workers within the curtain was traced by plotting their position every $60 \mathrm{~s}$ and tracing the path using Photoshop CS5 software.

\subsection{Age-related changes in curtain activities and onset of flight behavior}

We performed one experiment to monitor the agedependent appearance of $A$. florea workers on the curtain and crown area, and the age at onset of flight behavior. We introduced 150 individually marked 1day-old workers that had been collected from the comb of a second colony that was kept in an incubator at $37{ }^{\circ} \mathrm{C}$. We observed the appearance of the marked workers on the curtain and crown every third day for a period of 62 days (i.e., total of 21 observations). On the test days, the colony was observed twice, once in the morning from 1100-1230 hours and then in the afternoon from 1500-1600 hours. For the cumulative analysis, each bee was counted once for each of the three different activities (presence on curtain, presence on 
crown, and flying as a proxy for foraging) when she was first observed performing the respective activities. The crown area is the top-most part of the A. florea nest that is wrapped around the tree branch. This part of the nest contains only honey cells, and it is the area where the dance communication takes place and foragers leave the nest for a foraging trip (Ruttner 1988; Oldroyd and Wongsiri 2006). Thus, the crown comprises areas similar to the dance floor and the honey storage in A. mellifera nests, and one might expect this area to be populated by middle-aged workers.

\section{RESULTS}

\subsection{Occurrence and temporal dynamics of MFA}

During daily monitoring of $A$. florea colonies, we observed massed flight activities (MFA) similar to those described for A. dorsata and A. laboriosa. All of the recorded MFAs occurred between 1130 and 1500 hours and all colonies performed only one MFA during the daily observational period (Figure 1a). For one of the colonies, we succeeded in monitoring the daily occurrence of MFAs for a period of 3 months. In the first 6 weeks of the experiment, the colony performed MFA every third to fourth day and then it changed to perform MFA on every day. Interestingly, timings of MFAs were more consistent after the change in MFA frequency. Furthermore, the change in MFA frequency co-occurred with an increase in the mean daily temperature (Figure 1a) and an increase in the thickness of the curtain (i.e. increase in colony size, pers. observation). Our observations ended when the colony absconded. Time of absconding (1500 hours) was different from the time of MFA on the days preceding the day of absconding (Figure 1a).

The clear sign of a colony initiating a MFA was the occurrence of long-lasting wider gaps in the bee curtain accompanied with an increase in general activity (Figure 1b). Detailed analysis of the MFA video recordings indicated that the opening of the gaps is preceded by an increase in the number of down walking workers (Figure 1c). Finally, at the start of the massed flight takeoff, the curtain disintegrated, and chains of bees were visible. Eventually, the chains of bees either stayed or reduced in length (Figure 2). The workers flew up to a height of 15-20 m but did not leave the proximity of the nest. After some time, the bees came down and hovered in front of the nest until they started to land on the comb again. We did not observe any massive defecation. Workers landing back on the comb were oriented in different directions, and at some point of time, each of them started to orient head upward which finally lead to the reorganization of the curtain (Figure 1b). Duration of MFAs (i.e. flight activity and reorientation of the curtain) ranged from 5 to $9 \mathrm{~min}$ (average $7 \mathrm{~min} \pm 1.2 \mathrm{~min}, 19 \mathrm{MFAS}$ of 4 colonies). The whole process of the collective behavior, i.e., massed activity plus its initiation, took at least $20 \mathrm{~min}$ (see Figure 1c).

\subsection{Daily movement patterns of individual workers}

Analyses of the movement patterns of 21 individually identified workers showed that single bouts of staying on the outermost layer of the curtain range from a minimum of 2 to a maximum time of $179 \mathrm{~min}$ with an average of $35 \mathrm{~min}$. Furthermore, most of the observed workers appeared on the curtain at several times of the day (max. 23 appearances; average $=8 \pm 6$ ). While the majority of workers joined the curtain structure, some workers continuously walked on the curtain for most of the time (see bee 8, 16, and 22; Figure $3 a, b$ ).

Most workers that had left the outermost layer reappeared at a different location. Distance between the locations of disappearance and reappearance varied among individual bees. While in the curtain, position of workers slightly shifted with time (Figure 4, Bee 1 and 12), which is likely a consequence of the overall activity of workers leaving and joining the curtain.

\subsection{Age-related changes in curtain activities and onset of flight behavior}

During the experiment, we observed 127 out of 150 introduced workers. Workers started to appear in the outer layer of curtain on day 2 , and by day 5 , more than $50 \%$ of the 117 "curtain-observed" workers had been observed in the curtain. 
a

- Temperature record near colony during massed flight activity

- Mean daily temperature in Bangalore
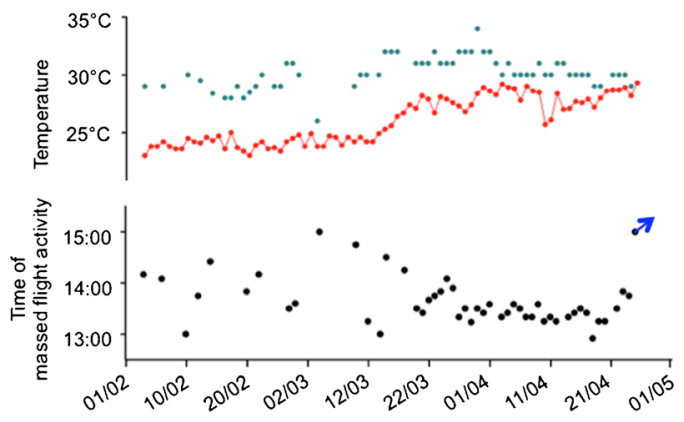

b

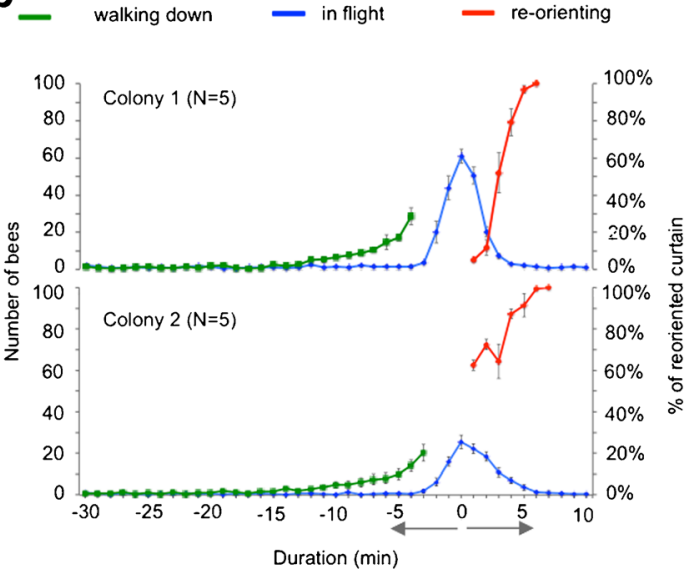

Figure 1. Temporal dynamics of massed flight activity (MFA) in Apis florea . a Occurrence of massed flight activity in one colony over a period of 3 months. Each black dot indicates one massed flight activity. The experiment ended when the colony absconded; the blue arrow indicates the time of absconding. Ambient temperature during the MFA (green dotted line) and mean daily temperature in Bangalore (red dotted line). b Temporal dynamics of three behaviors appearing during the process of the MFA: downward walking workers (green line), numbers of bees in flight (blue line), and percentage of comb area with oriented workers (red line). To compare MFAs of different days, we determined the time point of highest number of flying bees as $t 0$. This time point occurs at the end of the MFA when the bees are hovering in front of the nest. Error bars indicate standard error.

Similarly, the first workers appeared quite early (day 5 ) in the crown region, but only by day 20 , $50 \%$ of all the 106 "crown-observed" workers had appeared on the crown region. We observed the first flying workers at the age of 17 , and a second more pronounced increase in number of workers flying were observed after day 44 (Figure 5a). By the end of the experiment, we had observed 51 flying workers, and $50 \%$ of these had started flying after day 47. Except for one, all flying workers had been observed either on the curtain or the crown or on both before they started to fly (Figure 5b).

We stopped the experiment on day 62 and flash froze the whole colony. At that time point, we found 56 bees still present in the colony. Out of those 56,25 bees had been observed flying, 22 on the crown, 7 only on the curtain, and 2 had never been observed on any of the observation dates (tab 1). Thus, by the end of the experiment, we had observed a total of 127 workers, and 82 of those had either been observed flying (51) or were on

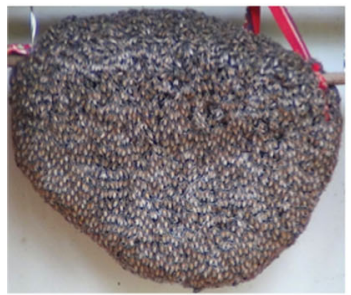

"quiet" curtain

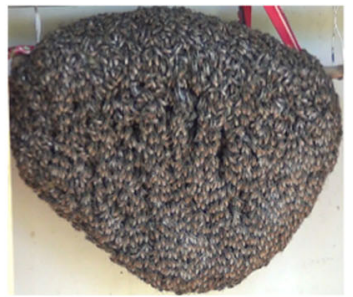

appearing grooves

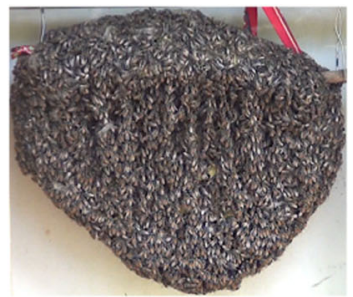

chains visible

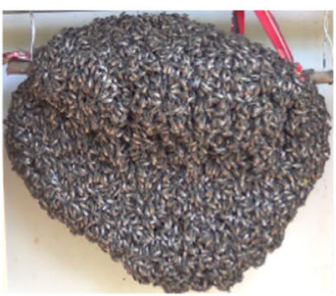

disoriented bees

Figure 2. Major structural changes of the curtain during the massed flight activity. "Quiet curtain" ( $-6 \mathrm{~min})$, "appearing groves" (-6- $-3 \mathrm{~min})$, "Chains of bees visible" (-3- -1 min), "disoriented bees" after landing $(+1-+2 \mathrm{~min})$. Numbers in brackets indicate time period given in Figure $1 \mathrm{~b}$. 
a
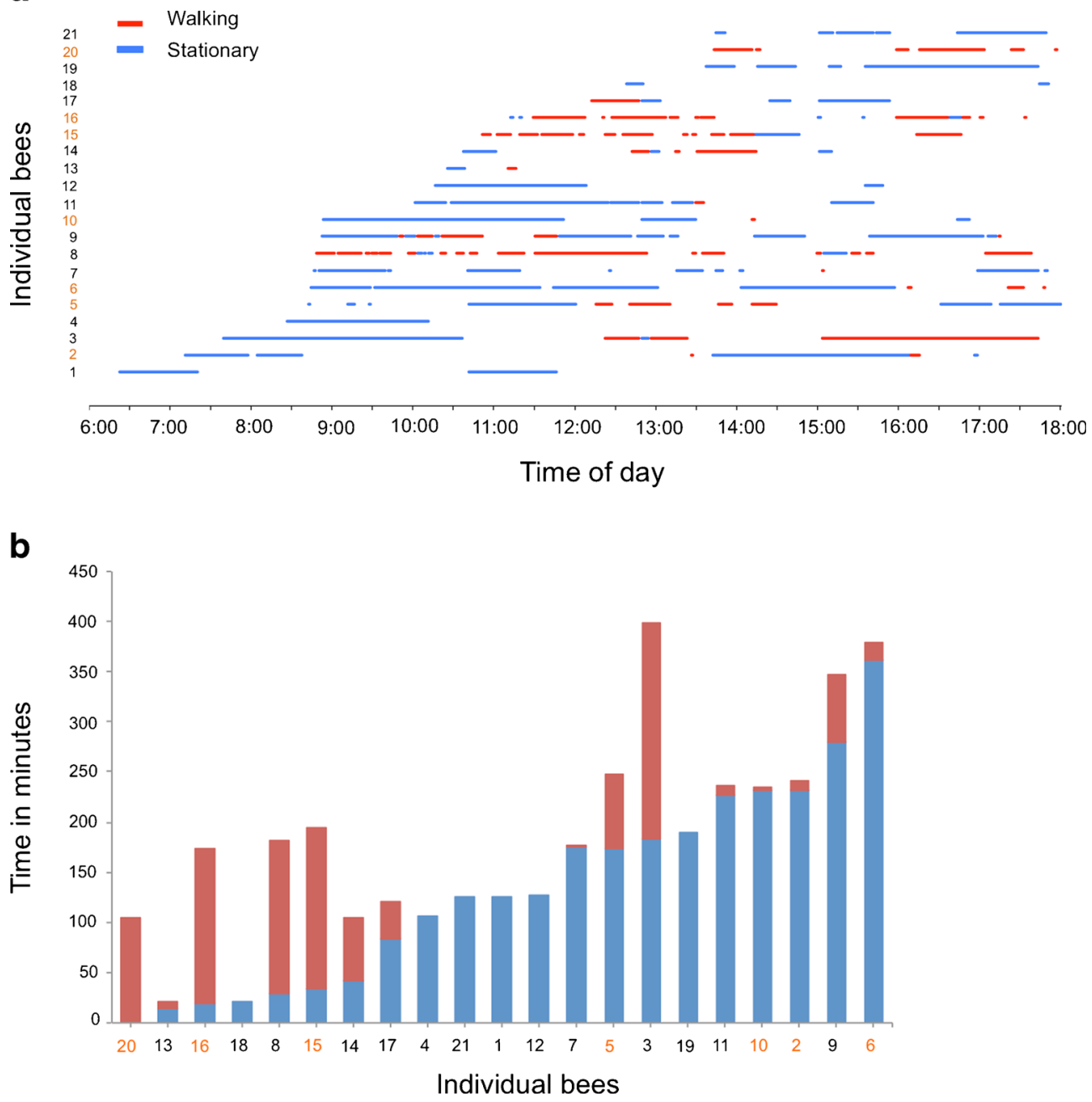

Figure 3. Daily activity of individually identified workers in the outer layer of the bee curtain a Daily activity patterns of 21 individual identified workers from two colonies (orange and back numbers). Time spent interconnected in the curtain (blue line) and time walking on the curtain (red line). b Each bar shows total time a bee was observed on the curtain. Sitting in the curtain (blue) and walking on the curtain (red).

the crown before the onset of flying (31). These numbers suggest that we likely lost 45 workers after they had been observed in the curtain and/or on the crown (see Table I).

\section{DISCUSSION}

\subsection{Occurrence and temporal dynamics of MFA}

In A. florea, massed flight activity (MFA) comprises four visually observable phases: (1) appearance of downward walking bees on the bee curtain, (2) long-lasting opening of gaps, (3) massed flight activity, and (4) landing and reorientation of the workers. Massed flight activity, i.e., massed flight take off, is only one part of a longer process of collective behavior. The initial decision to perform a massed flight must have been made before the occurrence of all visually observable processes.

Description of MFAs in the giant honey bee, A. dorsata and A. laboriosa, mostly focused on the flight behavior, but there are two studies that reported an increased disorder and the occurrence of 
Bee 1
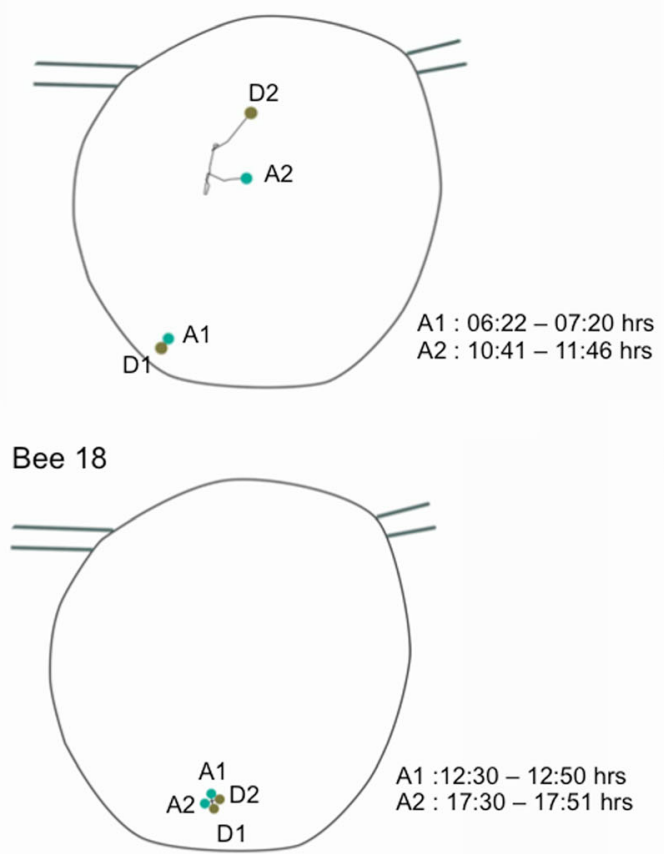

A : Appearance

D: Disappearance
Bee 12

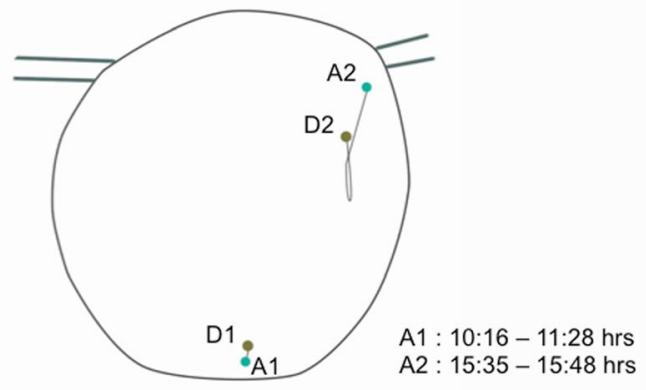

Bee 19

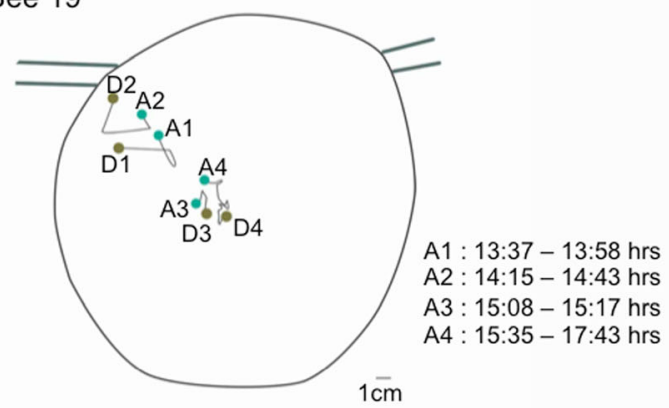

Figure 4. Spatial movement patterns of individual workers on the curtain (bees 1, 12, 18, and 19 shown from Figure 3). Bee appeared on the curtain (green dot); bee disappeared from the curtain (brown dot). Numbers indicate the order of appearance and disappearance. Continuous line indicates the shift in the bee's position although she was interconnected in the curtain.

gaps in the bee curtain shortly before a MFA (Woyke et al. 2003, 2004). MFAs in A. florea and the giant honey bee species appear to be very similar with respect to flight behavior, but there might be differences in the initiation and preparation of the MFA due to differences in the organization of the curtain and the nest. Furthermore, our observations suggest that the species differ with respect to the number of MFAs per day. A. dorsata and A. laborisa perform several MFAs per day, while we observed only one MFA per day in A. florea (Woyke et al. 2005). However, some of the studies on the giant honey bees do not clearly distinguish between MFAs and mating flights in nest congregations (see comment by Kastberger et al. 1996).

\subsection{Comments on the function of MFA}

So far, three different hypotheses about the function of MFA in open-nesting honey bee species have been proposed: (a) MFA is homologous to the orientation flights ("Vorspiel") of young workers (Kastberger et al. 1996); (b) MFA leads to periodical rearrangement of worker position in the curtain (Kastberger et al. 1996); and (c) MFAs are involved in temperature regulation in the nest (e.g., Mardan and Kevan 1989). We think that the orientation flight hypothesis is not very plausible as this behavior is longer than 6 or 7 min (Schua 1952; Seeley et al. 1979). The rearrangement hypothesis does not fit with our finding that there is a permanent turnover of workers in the curtain of $A$. florea colonies. Furthermore, Meyer (1956) reported a similar turnover mechanism in A. mellifera swarms.

This leaves us with the hypothesis that MFAs have something to do with colony thermoregulation. Similar to the observations by Woyke et al. (2004), we found an increase in MFAs with colony growth and an increase in the thickness of the 

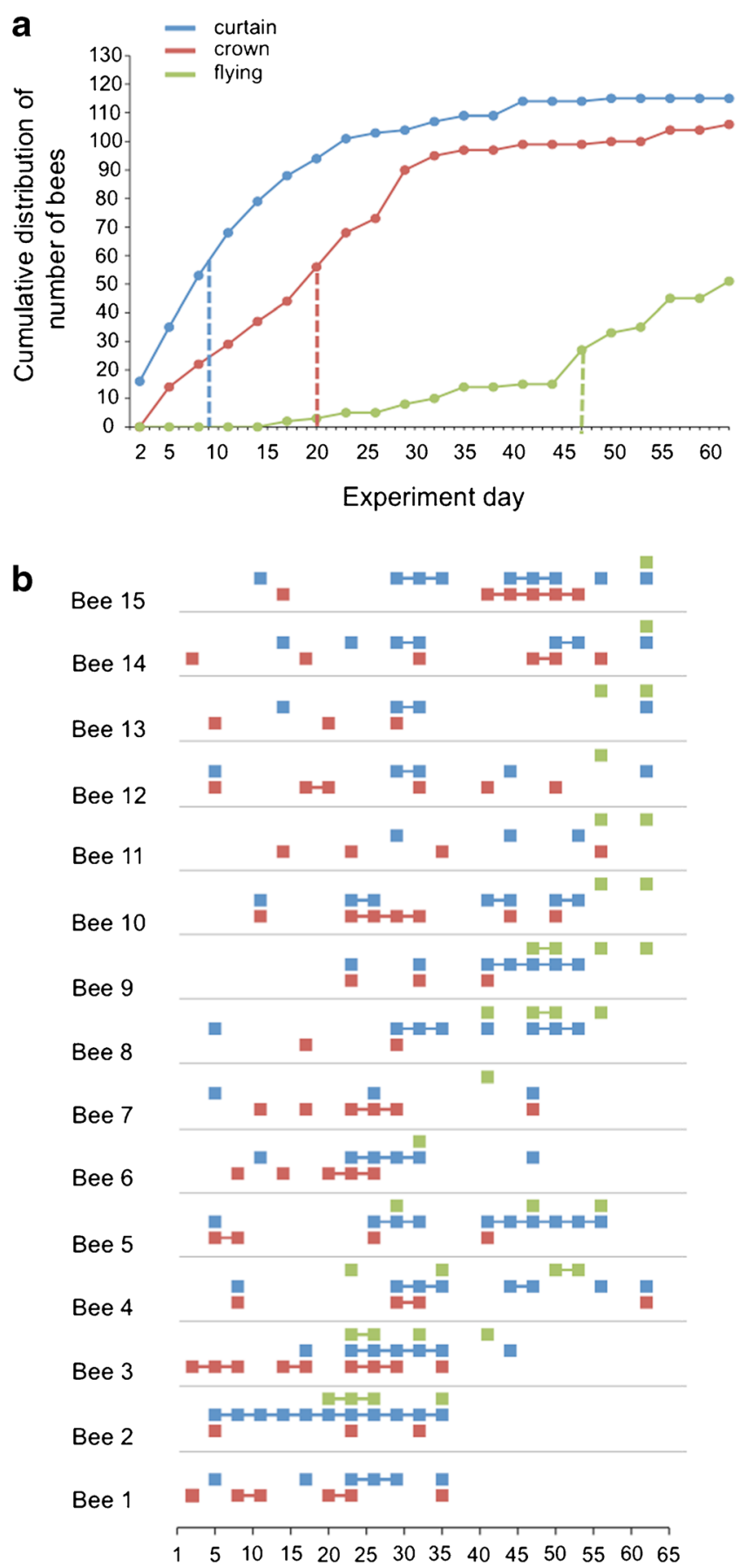

Figure 5. Age-related changes in curtain activities and onset of flight behavior. a Cumulative number of bees in the curtain, crown, and observed flying. Colored dashed lines indicate day at which $50 \%$ of the observed workers had been observed to the respective behavior. Fifty percent of the total number of introduced day olds (gray dashed line). b Sequence of observations for individual workers. Each square indicates that the individual bee was observed on the curtain, the crown, or flying. Connections between squares indicate that the bees were observed on consecutive days. 
Table I. Summary: Age-related changes in curtain activities and onset of flight behavior.

\begin{tabular}{lllll}
\hline & $\begin{array}{c}\text { Total number } \\
(150 \text { bees })\end{array}$ & Curtain & Crown & Flying \\
\hline No. of bees observed & 127 & 117 & 106 & 51 \\
$\begin{array}{l}\text { No. of bees still present on day 62 listed } \\
\text { according to their last recorded activity state }\end{array}$ & 56 & 7 & 22 & 25 \\
Day the first bee was observed & & 2 & 5 & 17 \\
Day at which 50 \% of the bees were observed & 8 & 20 & 47 \\
\hline
\end{tabular}

curtain. Both factors likely affect heat accumulation within the curtain itself. We did not find a correlation between MFAs and the ambient temperature at the times of MFAs (Woyke et al. 2004), but mean daily temperature in Bangalore had increased shortly before the change in MFA frequency (Figure 1a). Somewhat surprising is the finding that the change in MFA frequency is accompanied with a strong decrease in the variation of the MFA timings. One possibility is that the increase in mean temperature was accompanied with a more uniform temperature dynamic in the following days. Finally, the fact that the colony absconded at the end of the experiment suggests that it must have had only a small amount of brood if any during the last days. If so, one might speculate that MFAs are not primarily involved in thermoregulation of the brood area but the regulation of the temperature in the curtain itself.

\subsection{Daily movement patterns of individual workers}

For the observer, the bee curtain of A. florea and $A$. dorsata colonies easily appears to be quiescent (Dyer and Seeley 1991; Kastberger et al. 2011). However, our marking experiments clearly indicated that there is a frequent turnover of workers in the outermost layers (Figures 4). Bees stayed for 2 to $179 \mathrm{~min}$ with an average of $35 \mathrm{~min}$ in the outer layer. Our observations resemble the descriptions of A. mellifera worker behavior in swarm clusters. Meyer (1956) reported that bees in the outer layer of the swarm cluster constantly rearrange and two-thirds of all bees have been exchanged within $10 \mathrm{~min}$. Our results suggest a slower turnover rate in A. florea curtains; however, it is unclear whether this difference is a species-specific difference or due to differences between swarms (=cluster of adult bees) and curtains (=cluster of adult bees + comb and brood). Worker turnover on the outermost layer as well as constant positional changes of individuals in the curtain (or swarm) likely have different functions, most importantly feeding (replenish its energy stores) and warming up, but it may also be necessary for communication and knowledge of the state of the colony. Furthermore, there might be an architectural reason. If we regard the curtain as a dynamic structure that is made out of small moveable units, then it might be a structural rule that everyone has to move around to keep the overall structure constant.

\subsection{Comments on the organization of the bee curtain in Apis florea}

Most, if not all, studies on open-nesting species state that the bee curtain is composed of several layers of bees connected in a mesh-like structure (Anderson et al. 2002; Kastberger et al. 2011). However, our observations of MFAs in A. florea suggest that the bee curtain may permanently consist of the two different structural units - the meshlike outermost layers and an inner core composed of chains of bees - or that the bees in the curtain can arrange themselves into these two collective structures depending on environmental conditions or behavioral context (see also Figure S2). Meyer (1956) and Heinrich (1981) reported that A. mellifera swarms and winter clusters are composed of a mantle and a core and that the core is made of strings and the mantle is made of mesh-like layers of bees. Mesh-like layers certainly allow a tighter sealing of the surface, whereas chains might allow keeping more bees per space and might also 
be able to generate more force to hold more weight (Kastberger et al. 2011; Cully and Seeley 2004).

\subsection{Age-related changes in curtain activities and onset of flight behavior}

Although detailed comparative studies on agepolyethism are still lacking, preliminary observations suggest that the general pattern is the same in all honey bee species (Roepke 1930; Perk 1973; Otis et al. 1990; Dyer and Seeley 1991). Young workers are involved in hive tasks, and older workers become foragers. However, there might be considerable differences in the onset of foraging (Otis et al. 1990; Dyer and Seeley 1991).

In our study, almost all of the marked workers were first observed in the curtain or the crown before starting flight behavior (Figure 5b). In contrast to Dyer and Seeley (1991), we did not find a close temporal connection between appearing in the crown region and first flight behavior. We observed first flight behavior at an age of 17-26 days (10\% of all workers observed flying), but $50 \%$ of the workers were observed flying for the first time at an age older than 47 days. In contrast, A. mellifera workers were shown to start orientation flights at an age of 3-14 days (mean 6.2 days) during summer time (Capaldi et al. 2000). In the same experiment, bees were observed foraging at the age of 14. In general, one may assume that workers start foraging around the age of 20 days. Our experiment was conducted at National Center for Biological Sciences, Bangalore, from late January to late March, a period of high abundance of flowering plants (Nagaraja and Rajagopal 1999). Given our results, behavioral maturation of foragers in A. florea might be two to three times longer than that in A. mellifera. Dyer and Seeley (1991) suggested that the difference in worker maturation is a consequence of the bee curtain, which inhibits workers from doing other tasks, e.g., nursing. Without having to maintain a curtain, cavity-nesting species can invest more work forces into reproduction and thus increase worker turnover. This increase in population growth can compensate for increased loss of adult workers and thus allows earlier onset of foraging.

Winston (1987) pointed out that all published data on onset of foraging in A. mellifera indicate a range from 3 to 65 days at which workers can become foragers. Otis et al. (1990) reported an age range from 15 to more than 35 days for onset of foraging in A. dorsata. All this data suggests that there is a striking plasticity in the onset of foraging in all honey bee species.

At the end of our experiment (after 62 days), we still found 56 workers $(37.3 \%)$ of the introduced day olds in the colony. In Dyer and Seeley's (1991) experiment, $19.6 \%$ of the introduced bees were still alive at the end of their experiment at day 42. Ruttner (1988) reported an average life span of 61.2 days and a maximal life span of 118 days for $A$. florea workers kept in an indoor flight room. Life span of $A$. mellifera workers ranges from $15-38$ days in the summer to 30 60 days in the spring, and 150-200 days in the winter (see Remolina and Hughes 2008). Some authors suggested that a major factor determining life span in honey bees is age of onset of foraging (Rueppell et al. 2007). Thus, differences in worker life span between studies might also be due to differences in colony state and environmental conditions affecting onset of foraging. Careful comparative studies are needed to verify whether there are species-specific differences in agepolyethism and longevity among honey bee species or whether the reported differences are just a product of colony state and phenotypic plasticity.

\section{ACKNOWLEDGMENTS}

The project was funded by the National Center for Biological Sciences, institutional funding (to $\mathrm{AB}$ ). We thank Hanumantha Raju for finding and collecting A. florea colonies. Vandana G Pawar, Ankitha Sengupta, Leanna Rose Joy, and Ravi Kumar Boyapati helped with the experiments. We thank Ebi Antony George and Divya Ramesh for suggestions improving the manuscript.

Dynamique dans l'espace et dans le temps du "rideau d'abeilles" chez Apis florea, espèce construisant un nid ouvert

Apis florea / protection du nid / activité de vol en masse / ouvrières / comportement collectif

Strukturelle und zeitliche Dynamik des Bienenvorhangs in der frei brütenden Honigbienenart Apis florea

Apis florea / frei brütend / Bienenvorhang / Flugaktivität 


\section{REFERENCES}

Anderson, C., Theraulaz, G., Deneubourg, J.L. (2002) Selfassemblages in insect societies. Insect Soc. 49, 99-110

Batra, S.W. (1996) Biology of Apis laboriosa smith, a pollinator of apples at high altitude in the great Himalaya range of Garhwal, India, (Hymenoptera: Apidae). J. Kansas Entomol. Soc. 69, 177-181

Capaldi, E.A., Smith, A.D., Osborne, J.L., Fahrbach, S.E., Farris, S.M., Reynolds, D.R., Edwards, A.S., Martin, A., Robinson, G.E., Poppy, G.M., Riley, J.R. (2000) Ontogeny of orientation flight in the honeybee revealed by harmonic radar. Nature 403 (6769), 537-540

Cully, S.M., Seeley, T.D. (2004) Self-assemblage formation in a social insect: the protective curtain of a honey bee swarm. Insect Soc. 51 (4), 317-324

Dyer, F.C., Seeley, T.D. (1991) Nesting behavior and the evolution of worker tempo in four honey bee species. Ecology 72, 156-170

Fuchs, S., Tautz, J. (2011) Colony defence and natural enemies. In: Hepburn, H.R., Radloff, S.E. (eds.) Honeybees of Asia, pp. 369-395. Heidelberg, New York, Springer Verlag, Berlin

Heinrich, B. (1981) The mechanisms and energetics of honeybee swarm temperature regulation. J. Exp. Biol. 91, 25-55

Hepburn, H.R., Pirk, C.W.W., Duangphakdee, O. (2014) Honeybee nests. Composition, structure, function. Springer Verlag, Berlin, Heidelberg, New York

Kastberger, G., Winder, O., Hoetzl, T., Raspotnig, G. (1996) Behavioural features of a periodic form of massed flight activity in the giant honeybee Apis dorsata. Apidologie 27, 381-395

Kastberger, G., Weihmann, F., Hoetzl, T. (2011) Selfassembly processes in honeybees: the phenomenon of shimmering. In: Hepburn, H.R., Radloff, S.E. (eds.) Honeybees of Asia, pp. 3397-443. Springer Verlag, Berlin, Heidelberg

Mardan, M., Kevan, P.G. (1989) Honeybees and "yellow rain". Nature 341, 191

Meyer, W. (1956) Arbeitsteilung im bienenschwarm. Insect Soc. 3, 303-324

Nagaraja, N., Rajagopal, D. (1999) Colony establishment, nesting, and foraging activity of little honey bee Apis florea F. (Hymenoptera: Apidae). J. Entomol. Res 23 (4), 331-338

Oldroyd, B.P., Wongsiri, S. (2006) Asian honey bees biology, conservation, and human interactions. Harvard University Press, Cambridge (Mass)
Otis, G.W., Mardan, M.B., McGee, K. (1990) Age polyethism in Apis dorsata. In proceedings of the 11 th international congress, p. 378. IUSSI, Bangalore

Perk, J. (1973). Arbeitsteilung bei Apis cerana. Examensarbeit, Inst. BK, Oberursel, Germany. (cited in Abrol, D.P. (2013) Asiatic Honeybee Apis cerana Biodiversity Conservation and Agricultural Production. Springer Verlag, Dordrecht.)

Phiancharoen, M., Duangphakdee, O., Hepburn, H.R. (2011) Biology of nesting. In: Hepburn, H.R., Radloff, S.E. (eds.) Honeybees of Asia, pp. 109-131. Springer Verlag, Berlin, Heidelberg

Remolina, S.C., Hughes, K.A. (2008) Evolution and mechanisms of long life and high fertility in queen honey bees. Age 30, 177-185

Roepke, W. 1930. Beobachtungen an indischen Honigbienen insbesondere an Apis dorsata F. (Meded. Landbouwhoogeschool Wageningen, 34 [6], :1-28). (cited by W. Meyer, 1956)

Rueppell, O., Bachelier, C., Fondrk, M.K., Page, R.E. (2007) Regulation of life history determines lifespan of worker honey bees (Apis mellifera L.) Exp. Geront 42 (10), 1020-1032

Ruttner, F. (1988) Biogeography and taxonomy of honeybees. Springer-Verlag, Berlin

Schua, L. (1952) Untersuchungen über den Einfluss meteorologischer Elemente auf das Verhalten der Honigbienen (Apis mellifica). Z. Vergl. Physiol. 34 (8), 258-277

Seeley, T.D., Morse, R.A. (1976) The nest of the honey bee (Apis mellifera L.). Insect. Soc. 23, 495-512

Seeley, T.D., Morse, R., Visscher, P.K. (1979) The natural history of the flight of honey bee swarms. Psyche 86(2-3), 103-113

Seeley, T.D., Seeley, R.H., Akratanakul, P. (1982) Colony defense strategies of the honeybees in Thailand. Ecol. Monogr. 52 (1), 43-63

Winston, M.L. (1987) The biology of the honey bee. Harvard University Press, Cambridge

Woyke, J., Wilde, J., Wilde, M. (2003) Periodic mass flights of Apis laboriosa in Nepal. Apidologie 34, 121-127

Woyke, J., Kruk, C., Wilde, J., Wilde, M. (2004) Periodic mass flights of the giant honey bee, Apis dorsata. J. Apic. Res. 43 (4), 181-186

Woyke, J., Wilde, J., Reddy, C.C., Nagaraja, N. (2005) Periodic mass flights of the giant honey bee Apis dorsata in successive days at two nesting sites in different environmental conditions. J. Apic. Res. 44 (4), 180-189 